\title{
The Dialysis Sodium Gradient: A Modifiable Risk Factor for Fluid Overload
}

\author{
Emilie Trinh Catherine Weber \\ Division of Nephrology, McGill University Health Centre, Montreal, QC, Canada
}

\author{
Keywords \\ Hemodialysis · Sodium · Sodium gradient · Fluid overload · Interdialytic weight gain · \\ Ultrafiltration
}

\begin{abstract}
Background: Fluid overload in patients on conventional hemodialysis is a frequent complication, associated with increased cardiovascular morbidity and mortality. The dialysate sodium prescription is a potential modifiable risk factor. Our primary objective was to describe associations between dialysate-to-serum sodium gradient and parameters of fluid status. A secondary objective was to evaluate the 6 -month risk of hospitalization and mortality in relation to sodium gradient. Methods: We performed a cross-sectional study of 110 prevalent conventional hemodialysis patients at a single center. The associations of sodium gradient with interdialytic weight gain index (IDWG\%), ultrafiltration (UF) rate, and blood pressure (BP) were analyzed. Results: The mean serum sodium gradient was $4.6 \pm 3.6 \mathrm{mEq} / \mathrm{L}$. There was a direct correlation between sodium gradient and IDWG\% $(r=0.48, p<0.01)$ as well as UF rate $(r=$ $0.44, p<0.01)$. In a logistic regression model, a $1 \mathrm{mEq} / \mathrm{L}$ higher sodium gradient was associated with increased risk of IDWG\% $>3 \%$ (OR 1.33, $p<0.01$ ) and increased risk of UF rate $>10$ $\mathrm{mL} / \mathrm{kg} / \mathrm{h}$ (OR 1.16, $p=0.03$ ), but there were no associations with intradialytic hypotension, intradialytic hypertension or BP. No significant differences were found with 6-month hospitalization or mortality risk in relation to sodium gradient. Conclusion: A higher sodium gradient was associated with significant increases in IDWG and UF rates, known to be associated with poor outcomes, but was not associated with intradialytic hypotension. Individualizing the dialysate sodium prescription to minimize sodium gap may lead to less fluid overload in conventional hemodialysis patients.


Trinhand Weber: The Dialysis Sodium Gradient: A Modifiable Risk Factor for Fluid Overload

\section{Introduction}

It is estimated that up to one-third of patients on conventional hemodialysis and peritoneal dialysis are volume overloaded $[1,2]$. Reasons for this are multifactorial and include limitations of physical examination and current dialysis technologies to accurately diagnose volume overload, patient indiscretion with diet, and dialysis sodium prescription [3-6]. It has been demonstrated that patients who are $>2.5 \mathrm{~L}$ volume overloaded at the start of hemodialysis have a hazard ratio (HR) of 2.1 for mortality and this is independent of blood pressure (BP) [2]. Several mechanisms have been proposed to explain how volume overload leads to increased mortality in the dialysis population, mostly linking volume overload to left ventricular hypertrophy with associated cardiovascular events and more recently, to inflammation which in turn leads to accelerated atherosclerosis [2, 7-9]. Interdialytic weight gain (IDWG) is often used as a surrogate marker for fluid overload and studies have shown that a higher IDWG\% (ratio of IDWG to dry weight) predicts cardiovascular events (IDWG 3.0-3.9\% and HR 1.80 [95\% CI 0.95-3.41]; IDWG >4.0\% and HR 1.93 [95\% CI 1.02-3.64]) [10]. In addition, higher ultrafiltration (UF) rates of $>10 \mathrm{~mL} / \mathrm{kg} / \mathrm{h}$ have also been shown to increase mortality [11]. Higher UF rates and IDWG may also lead to more frequent episodes of intradialytic hypotension, which can be linked to vascular access complications, and inadequate dialysis, but most importantly increased cardiovascular morbidity and mortality $[12,13]$.

The dialysis prescription and particularly the dialysate sodium concentration are critical to maintain a euvolemic state. While various dialysate sodium concentrations have been used throughout the history of dialysis, recent studies have shown that the potential benefits of using a higher dialysate sodium with regard to hemodynamic stability are outweighed by increased thirst, higher IDWG, and higher pre-dialysis blood pressure (pre-BP) [14-16]. Furthermore, frequently used sodium modeling algorithms which typically involve tapering a high dialysate sodium concentration during hemodialysis can lead to greater IDWG and higher pre-BP [14]. The optimal dialysate sodium concentration, however, still remains unclear. Many dialysis centers around the world use a standard dialysate sodium concentration for all patients; a recent DOPPS report showed that $57 \%$ of hemodialysis facilities use a standard dialysate sodium prescription $[17,18]$. However, multiple studies have suggested that each dialysis patient may have a unique osmolar set point for plasma sodium and, therefore, dialysate sodium needs to be individualized [19-23]. More recently, there has been growing evidence that the sodium gradient (dialysate sodium minus predialysis serum sodium) is important to minimize in hemodialysis patients as it positively correlates with changes in BP during hemodialysis and IDWG [16, 19-25], with a sodium gradient of $>3$ $\mathrm{mEq} / \mathrm{L}$ particularly associated with adverse outcomes $[24,25]$.

The primary objective of our study was to describe associations between dialysate-toserum sodium gradient and various hemodialysis parameters of fluid status including BP, IDWG, and UF rates. A secondary analysis was performed to evaluate the 6-month risk of allcause hospitalization and mortality in relation to the sodium gradient.

\section{Methods}

We performed a cross-sectional study of all prevalent hemodialysis patients at the McGill University Health Centre including the Royal Victoria Hospital and Montreal General Hospital units with an index study date of January 26 or 27,2015 . We included all patients aged $>18$ years undergoing conventional hemodialysis treatments 3 times per week for $>6$ months with residual urine output $<150 \mathrm{ml} /$ day. Exclusion criteria were as follows: patients with dialysis treatment time $<3.5 \mathrm{~h}$, missed dialysis treatment in the last 2 weeks prior to index 
Trinhand Weber: The Dialysis Sodium Gradient: A Modifiable Risk Factor for Fluid Overload

study date, inadequate dialysis with $\mathrm{spKt} / \mathrm{V}<1.2$, change in target weight in the last 2 prior weeks, severe hyperglycemia (plasma glucose $>15 \mathrm{mmol} / \mathrm{L}$ ), liver cirrhosis, active infection or inflammatory disease, and hospitalization of any cause in the 4 weeks prior to the index study date.

For the predialysis serum sodium, the average of the last 3 monthly values prior to the index date was used. The sodium gradient was calculated using the prescribed dialysate sodium minus the average predialysis sodium. For the pre- and post-BP, IDWG, IDWG\% (IDWG/prescribed dry weight) and UF rates, the average of the last 6 hemodialysis treatments prior to the index date was used. A sodium gradient cutoff of $3 \mathrm{mEq} / \mathrm{L}(<3 \mathrm{vs} . \geq 3$ $\mathrm{mEq} / \mathrm{L}$ ) was used to categorize patients. The presence of intradialytic hypotension was defined as follows: in patients with a presystolic BP (pre-sBP) $<159 \mathrm{~mm} \mathrm{Hg}$, reaching a nadir of sBP $<90 \mathrm{~mm} \mathrm{Hg}$, and in patients with a pre-sBP $>160 \mathrm{~mm} \mathrm{Hg}$, reaching a nadir of $\mathrm{sBP}<100$ $\mathrm{mm} \mathrm{Hg}$ in at least $30 \%$ of treatments. This definition was used as it has been shown to be associated with cardiovascular outcomes [11]. Intradialytic hypertension was defined as post-sBP - pre-sBP >0 [26].

\section{Statistical Analysis}

Baseline demographics and clinical characteristics are presented as means or medians and proportions, as appropriate, based on a sodium gradient $>3$ or $\leq 3 \mathrm{mEq} / \mathrm{L}$. Comparisons were tested using the $\chi^{2}$ or Fisher exact test for categorical variables, and the Student $t$ test for parametric variables. Correlations were assessed with the Pearson product-moment coefficient. The associations between sodium gradient and IDWG, UF rates, intradialytic hypotension and intradialytic hypertension were also examined using a logistic regression analysis. $p$ values of $<0.05$ were considered statistically significant. All analyses were performed using SPSS version 20.0 (IBM Corp., USA).

\section{Results}

A total of 194 patients were screened for inclusion. After excluding the following patients (dialysis treatment $<3.5 \mathrm{~h}[n=16]$, missed dialysis treatment $[n=8]$, inadequate dialysis $[n=$ $1]$, recent change in target weight $[n=2]$, severe hyperglycemia $[n=11]$, liver cirrhosis $[n=$ $3]$, active infection or inflammatory disease [ $n=9]$, and hospitalization in the 4 weeks prior to index date $[n=34]), 110$ patients were included in the analysis.

\section{Baseline Characteristics}

The overall mean serum sodium gradient was $4.6 \pm 3.6 \mathrm{mEq} / \mathrm{L}$ with a mean predialysis sodium of $137.4 \pm 2.5 \mathrm{mEq} / \mathrm{L}$ and a mean dialysate sodium of $142.0 \pm 3.0 \mathrm{mEq} / \mathrm{L}$. Baseline patient characteristics are presented in Table 1. There was a higher proportion of males in patients with a sodium gradient $\leq 3 \mathrm{mEq} / \mathrm{L}$ compared to patients with a gradient $>3 \mathrm{mEq} / \mathrm{L}$ (71.1 vs. $50.8 \%, p=0.05$ ). The mean predialysis serum sodium (139 vs. $137 \mathrm{mEq} / \mathrm{L}, p<0.01$ ) and the mean dialysate sodium ( $140 \mathrm{vs.} 144 \mathrm{mEq} / \mathrm{L}, p<0.01$ ) were also significantly different among patients with a sodium gradient $\leq 3 \mathrm{mEq} / \mathrm{L}$ compared to those with a gradient $>3$ $\mathrm{mEq} / \mathrm{L}$. Furthermore, there were no patients with a predialysis serum sodium $<135 \mathrm{mEq} / \mathrm{L}$ among patients with a gradient $\leq 3 \mathrm{mEq} / \mathrm{L}$, whereas they represented $23 \%$ of the patients with a gradient $>3 \mathrm{mEq} / \mathrm{L}$. All other baseline characteristics were similar.

\section{Hemodialysis Characteristics}

When hemodialysis characteristics were compared (Table 2), the mean IDWG\% was significantly lower in patients with a gradient $\leq 3 \mathrm{mEq} / \mathrm{L}$ compared with $>3 \mathrm{mEq} / \mathrm{L}$ (2.4 vs. 
Trinhand Weber: The Dialysis Sodium Gradient: A Modifiable Risk Factor for Fluid Overload

Table 1. Baseline characteristics

\begin{tabular}{|c|c|c|c|}
\hline & $\begin{array}{l}\text { Na gradient } \leq 3 \mathrm{mEq} / \mathrm{L} \\
(\mathrm{n}=45)\end{array}$ & $\begin{array}{l}\text { Na gradient }>3 \mathrm{mEq} / \mathrm{L} \\
(\mathrm{n}=65)\end{array}$ & $\begin{array}{l}p \\
\text { value }\end{array}$ \\
\hline Mean age, years & 67 & 69 & 0.44 \\
\hline Male sex, $n(\%)$ & $32(71.1)$ & $33(50.8)$ & 0.05 \\
\hline Primary renal disease, $n(\%)$ & & & 0.46 \\
\hline Diabetes & $16(35.6)$ & $25(38.5)$ & \\
\hline Hypertension & $11(24.4)$ & $13(20.0)$ & \\
\hline Glomerulonephritis & $6(13.3)$ & $10(15.4)$ & \\
\hline Polycystic kidney disease & $2(4.4)$ & $2(3.1)$ & \\
\hline Other & $10(22.2)$ & $15(23.1)$ & \\
\hline Access type, $n(\%)$ & & & 0.64 \\
\hline CVC & $22(48.9)$ & $35(53.8)$ & \\
\hline AVF & $20(44.4)$ & $28(43.1)$ & \\
\hline AVG & $3(6.7)$ & $2(3.1)$ & \\
\hline Mean dialysis vintage, years & 6.5 & 5.1 & 0.16 \\
\hline Mean dialysis time, $\mathrm{h}$ & 3.8 & 3.9 & 0.53 \\
\hline Mean dialysate sodium, $\mathrm{mEq} / \mathrm{L}$ & 140 & 144 & $<0.01$ \\
\hline Mean serum sodium, mEq/L & 139 & 137 & $<0.01$ \\
\hline Serum sodium subgroups, $n(\%)$ & & & $<0.01$ \\
\hline$<135 \mathrm{mEq} / \mathrm{L}$ & $0(0)$ & $15(23.1)$ & \\
\hline $135-139.9 \mathrm{mEq} / \mathrm{L}$ & $34(75.6)$ & $44(67.7)$ & \\
\hline$\geq 140 \mathrm{mEq} / \mathrm{L}$ & $11(24.4)$ & $6(9.2)$ & \\
\hline
\end{tabular}

AVF, arteriovenous fistula; AVG, arteriovenous graft; CVC, central venous catheter. $p$ values in bold are significant.

Table 2. Hemodialysis characteristics

\begin{tabular}{llcr}
\hline & $\begin{array}{l}\text { Na gradient } \leq 3 \mathrm{mEq} / \mathrm{L} \\
(n=45)\end{array}$ & $\begin{array}{l}\text { Na gradient >3 mEq/L } \\
(n=65)\end{array}$ & $\begin{array}{l}p \\
\text { value }\end{array}$ \\
\hline Mean pre-HD sBP, mm Hg & 136 & 139 & 0.40 \\
Mean pre-HD dBP, mm Hg & 64 & 62 & 0.44 \\
Mean post-HD sBP, mm Hg & 131 & 134 & 0.34 \\
Mean post-HD dBP, mm Hg & 64 & 64 & 0.94 \\
Mean IDWG\% - IDWG/TW & 2.4 & 3.5 & $<\mathbf{0 . 0 1}$ \\
Mean UF rate, mL/kg/h & 7.2 & 9.6 & $<\mathbf{0 . 0 1}$ \\
Intradialytic hypotension, $n(\%)$ & $8(17.8)$ & $12(18.5)$ & 0.93 \\
Intradialytic hypertension, $n(\%)$ & $12(26.7)$ & $28(43.1)$ & 0.08 \\
Mean number of BP medications & 1.5 & 1.4 & 0.47
\end{tabular}

BP, blood pressure; dBP, diastolic blood pressure; HD, hemodialysis; IDWG, interdialytic weight gain; sBP, systolic blood pressure; UF, ultrafiltration; TW, target weight. $p$ values in bold are significant.

$3.5 \%, p<0.01$ ). Similarly, the mean UF rate was also significantly lower in patients with a gradient $\leq 3 \mathrm{mEq} / \mathrm{L}(7.2 \mathrm{vs} .9 .6 \mathrm{~mL} / \mathrm{kg} / \mathrm{h}, p<0.01$ ). However, there was no difference in terms of pre- or post-BP, number of BP medication, episodes of intradialytic hypotension or presence of intradialytic hypertension between patients with a gradient $\leq 3$ and $>3 \mathrm{mEq} / \mathrm{L}$. 
Fig. 1. Sodium gradient and interdialytic weight gain. An increasing sodium gradient positively correlates with increased interdialytic weight gain (expressed as ratio of interdialytic weight gain to dry weight in percent). IDWG, interdialytic weight gain.

Trinhand Weber: The Dialysis Sodium Gradient: A Modifiable Risk Factor for Fluid Overload

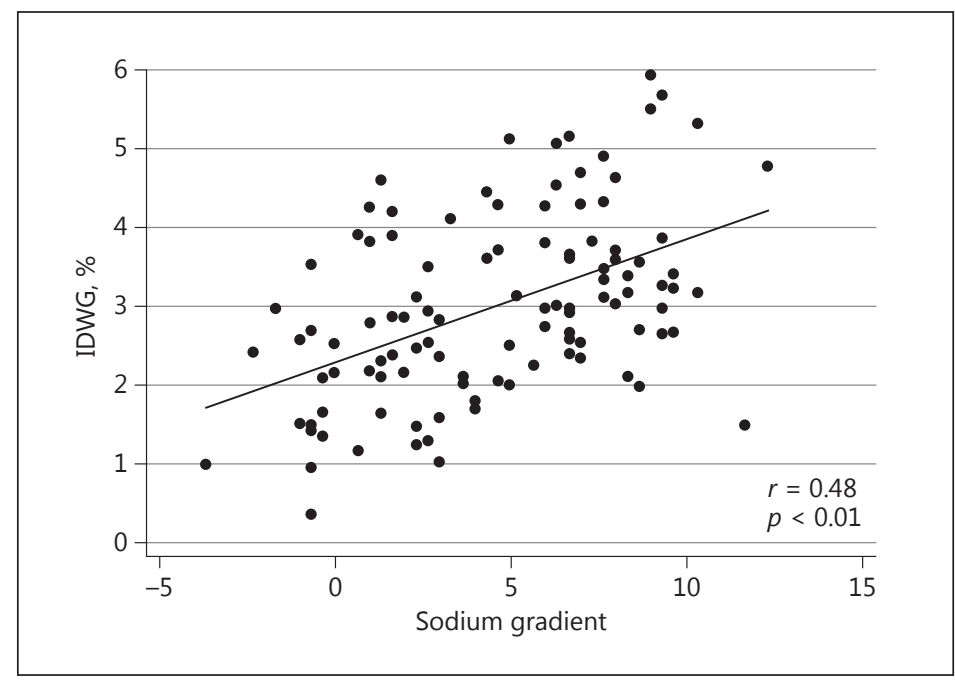

Table 3. Logistic regression per $1 \mathrm{mEq} / \mathrm{L}$ increase in sodium gradient

\begin{tabular}{llrr}
\hline & Odds ratio & 95\% CI & $p$ value \\
\hline UF rate $>10 \mathrm{~mL} / \mathrm{kg} / \mathrm{h}$ & 1.16 & $1.02-1.33$ & 0.03 \\
IDWG $>3 \%$ & 1.33 & $1.17-1.52$ & $<0.01$ \\
Intradialytic hypertension & 1.08 & $0.96-1.20$ & 0.19 \\
Intradialytic hypotension & 0.99 & $0.87-1.14$ & 0.98 \\
\hline
\end{tabular}

IDWG, interdialytic weight gain; UF, ultrafiltration.

\section{Sodium Gradient and IDWG}

The mean sodium gradient was significantly lower in patients with an IDWG $\%$ of $\leq 3 \%$ compared with $>3 \%$ ( 3.2 vs. $6.3 \mathrm{mEq} / \mathrm{L}, p<0.01$ ). The sodium gradient positively correlated with increasing IDWG\% $(r=0.48, p<0.01$, Fig. 1$)$. In a logistic regression analysis, a $1 \mathrm{mEq} / \mathrm{L}$ higher sodium gradient had an OR of 1.33 (95\% CI 1.17-1.52, $p<0.01$, Table 3) of $>3 \%$ IDWG\%.

\section{Sodium Gradient and UF Rates}

The mean sodium gradient was significantly lower in patients with UF rates $\leq 10 \mathrm{~mL} /$ $\mathrm{kg} / \mathrm{h}$ compared with $>10 \mathrm{~mL} / \mathrm{kg} / \mathrm{h}(4.2$ vs. $6.0 \mathrm{mEq} / \mathrm{L}, p=0.03)$ and the sodium gradient positively correlated with increasing UF rates ( $r=0.44, p<0.01$, Fig. 2). In a logistic regression analysis, a $1 \mathrm{mEq} / \mathrm{L}$ increase in sodium gradient carried an OR of 1.16 (95\% CI 1.02-1.33, $p=$ 0.03 , Table 3 ) for UF rates $>10 \mathrm{~mL} / \mathrm{kg} / \mathrm{h}$.

\section{Sodium Gradient and BP}

The mean sodium gradient was similar in patients with or without episodes of intradialytic hypotension. Moreover, the sodium gradient did not correlate with pre- or postdialysis $\mathrm{BP}$ values. A further logistic regression showed that the sodium gradient was not associated with increased risk of intradialytic hypertension or intradialytic hypotension (Table 3). 
Fig. 2. Sodium gradient and ultrafiltration rates. An increasing sodium gradient positively correlates with increased ultrafiltration rates (expressed in $\mathrm{mL} /$ $\mathrm{kg} / \mathrm{h})$. UF, ultrafiltration.

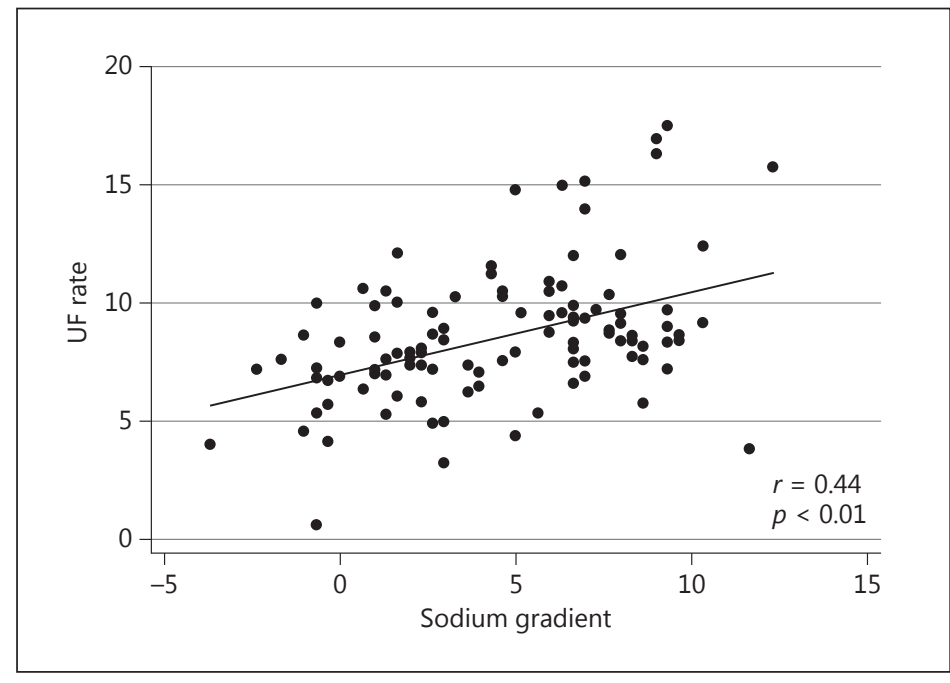

Patients with Predialysis Serum Sodium $<135 \mathrm{mEq} / \mathrm{L}$

When we excluded patients with a serum sodium $<135 \mathrm{mEq} / \mathrm{L}$, a positive correlation between the sodium gradient and IDWG\% $(r=0.49, p<0.01)$ or UF rates $(0.45, p<0.01)$ was still present.

\section{Risk of Death and Hospitalization}

With regard to the 6-month risk of hospitalization of all-cause mortality, there were proportionately more hospitalizations ( 30.8 vs. $17.8 \%, p=0.12$ ) and death ( 4.6 vs. $2.2 \%, p=$ 0.51 ) in patients with a sodium gradient $>3 \mathrm{mEq} / \mathrm{L}$, but these results did not reach statistical significance.

\section{Discussion}

Our study showed that a higher sodium gradient is associated with significant increases in IDWG and UF rates without an associated difference in intradialytic hypotensive episodes. We found no significant association between the sodium gradient and BP or number of antihypertensive medications. Thus, it appears that minimizing the sodium gradient is important given its association with these hemodialysis markers of fluid overload, which, in turn, are associated with increased cardiovascular morbidity and mortality. Our study suggests that a sodium gradient $\leq 3 \mathrm{mEq} / \mathrm{L}$ seems to be associated with favorable IDWG and UF rates. However, for the subset of patients with lower serum sodium levels $(<135 \mathrm{mEq} / \mathrm{L})$, the optimal sodium gradient cannot be concluded based on our study as all these patients had a gradient $>3 \mathrm{mEq} / \mathrm{L}$. This would particularly be important to investigate further, especially since lower serum sodium is associated with higher adjusted risk of death and a recent DOPPS study observed an interesting lower mortality risk in patients with serum sodium $<137$ $\mathrm{mEq} / \mathrm{L}$ dialyzed against a dialysate sodium $>140 \mathrm{mEq} / \mathrm{L}$ [18].

Our findings are consistent with the current literature demonstrating a positive correlation between the sodium gradient and parameters of fluid overload in hemodialysis patients $[15,16,19-21,23,27,28]$. These associations of a high sodium gradient with fluid overload are likely explained by a high dialysate sodium concentration leading to an elevated postdialysis serum sodium level with the consequence of increased thirst and fluid intake [29]. Our 
results are in keeping with Munoz Mendoza et al. [16] who also found a direct correlation between IDWG and sodium gradient with no associations with the frequency of intradialytic hypotension episodes. Other studies have equally shown that a sodium gradient of $>3 \mathrm{mEq} / \mathrm{L}$ is associated with fluid overload and adverse outcomes [24, 25]. Similarly, by decreasing dialysate sodium concentrations, Munoz Mendoza et al. [15] also demonstrated a significant decrease in IDWG without associated adverse events in patients undergoing in-center nocturnal hemodialysis. However, while Movilli et al. [26] showed an independent association between intradialytic hypertension and the dialysis sodium gradient, our results did not show a similar association, which could perhaps be related to our smaller sample size.

There are several strengths of this study. Firstly, at the time of this study, there were 2 different dialysate sodium strategies used at the 2 dialysis units which allowed for a range of sodium gaps to be studied. Although we did not collect data on the patients' cardiovascular status or echocardiogram results (if done), we limited our inclusion criteria to a stable cohort of prevalent hemodialysis patients. Our study does have some limitations given its singleinstitution nature and small sample size. Moreover, the finding of $23 \%$ of patients with serum sodium $<135 \mathrm{mEq} / \mathrm{L}$ only in the high sodium gradient group suggests possible confounding by indication which could have contributed to some of the results, especially the lack of differences in intradialytic hypotension. Patients with lower predialysis sodium may have been treated with higher dialysate sodium to potentially prevent this occurrence. The actual dialysate sodium was also not measured and others have demonstrated a large difference in the actual measured versus prescribed dialysate sodium with differences ranging from -13 to +6 $\mathrm{mEq} / \mathrm{L}[30]$. We used standard hemodialysis BP monitoring rather than home ambulatory BP, the latter of which is more accurate in the hemodialysis population [31,32]. Finally, an objective measurement of fluid status such as bioimpedance was not available.

Optimal fluid status is crucial in our dialysis population as it has an impact on quality of life, cardiovascular events, and mortality. Achieving euvolemia in our dialysis patients is therefore a high priority. Individualizing the dialysate sodium prescription to minimize the sodium gap may lead to less fluid overload in hemodialysis patients.

\section{Statement of Ethics}

This study was approved by the appropriate ethics committee and did not require informed consent.

\section{Disclosure Statement}

The authors declare no conflicts of interest. The results presented in this paper have not been published previously, in whole or part, except in abstract format.

\section{References}

$>1$ Hur E, Gungor O, Musayev O, Usta M, Toz H, Asci G, Ozkahya M, Duman S, Ok E: Bioimpedance spectroscopy for the detection of hypervolemia in peritoneal dialysis patients. Adv Perit Dial 2011;27:65-70.

$>2$ Wizemann V, Wabel P, Chamney P, Zaluska W, Moissl U, Rode C, Malecka-Masalska T, Marcelli D: The mortality risk of overhydration in haemodialysis patients. Nephrol Dial Transplant 2009;24:1574-1579.

-3 Agarwal R, Alborzi P, Satyan S, Light RP: Dry-weight reduction in hypertensive hemodialysis patients (DRIP): a randomized, controlled trial. Hypertension 2009;53:500-507.

4 Agarwal R, Andersen MJ, Pratt JH: On the importance of pedal edema in hemodialysis patients. Clin J Am Soc Nephrol 2008;3:153-158. 
Trinhand Weber: The Dialysis Sodium Gradient: A Modifiable Risk Factor for Fluid Overload

-5 Dou Y, Zhu F, Kotanko P: Assessment of extracellular fluid volume and fluid status in hemodialysis patients: current status and technical advances. Semin Dial 2012;25:377-387.

6 Reddan DN, Szczech LA, Hasselblad V, Lowrie EG, Lindsay RM, Himmelfarb J, Toto RD, Stivelman J, Winchester JF, Zillman LA, Califf RM, Owen WF Jr: Intradialytic blood volume monitoring in ambulatory hemodialysis patients: a randomized trial. J Am Soc Nephrol 2005;16:2162-2169.

7 Kalantar-Zadeh K, Regidor DL, Kovesdy CP, Van Wyck D, Bunnapradist S, Horwich TB, Fonarow GC: Fluid retention is associated with cardiovascular mortality in patients undergoing long-term hemodialysis. Circulation 2009;119:671-679.

-8 Velasco N, Chamney P, Wabel P, Moissl U, Imtiaz T, Spalding E, McGregor M, Innes A, MacKay I, Patel R, Jardine A: Optimal fluid control can normalize cardiovascular risk markers and limit left ventricular hypertrophy in thrice weekly dialysis patients. Hemodial Int 2012;16:465-472.

-9 Hung SC, Kuo KL, Peng CH, Wu CH, Lien YC, Wang YC, Tarng DC: Volume overload correlates with cardiovascular risk factors in patients with chronic kidney disease. Kidney Int 2014;85:703-709.

10 Lee MJ, Doh FM, Kim CH, Koo HM, Oh HJ, Park JT, Han SH, Yoo TH, Kim YL, Kim YS, Yang CW, Kim NH, Kang SW: Interdialytic weight gain and cardiovascular outcome in incident hemodialysis patients. Am J Nephrol 2014;39: 427-435.

-11 Flythe JE, Kimmel SE, Brunelli SM: Rapid fluid removal during dialysis is associated with cardiovascular morbidity and mortality. Kidney Int 2011;79:250-257.

12 Flythe JE, Xue H, Lynch KE, Curhan GC, Brunelli SM: Association of mortality risk with various definitions of intradialytic hypotension. J Am Soc Nephrol 2015;26:724-734.

13 Stefansson BV, Brunelli SM, Cabrera C, Rosenbaum D, Anum E, Ramakrishnan K, Jensen DE, Stalhammar NO: Intradialytic hypotension and risk of cardiovascular disease. Clin J Am Soc Nephrol 2014;9:2124-2132.

14 Mc Causland FR, Waikar SS: Optimal dialysate sodium: what is the evidence? Semin Dial 2014;27:128-134.

15 Munoz Mendoza J, Bayes LY, Sun S, Doss S, Schiller B: Effect of lowering dialysate sodium concentration on interdialytic weight gain and blood pressure in patients undergoing thrice-weekly in-center nocturnal hemodialysis: a quality improvement study. Am J Kidney Dis 2011;58:956-963.

16 Munoz Mendoza J, Sun S, Chertow GM, Moran J, Doss S, Schiller B: Dialysate sodium and sodium gradient in maintenance hemodialysis: a neglected sodium restriction approach? Nephrol Dial Transplant 2011;26: 1281-1287.

Basile C, Lomonte C: It is time to individualize the dialysate sodium prescription. Semin Dial 2016;29:24-27.

18 Hecking M, Karaboyas A, Saran R, Sen A, Horl WH, Pisoni RL, Robinson BM, Sunder-Plassmann G, Port FK: Predialysis serum sodium level, dialysate sodium, and mortality in maintenance hemodialysis patients: the Dialysis Outcomes and Practice Patterns Study (DOPPS). Am J Kidney Dis 2012;59:238-248.

19 Flanigan MJ: Role of sodium in hemodialysis. Kidney Int Suppl 2000;76:S72-S78.

-20 Flanigan MJ: How should dialysis fluid be individualized for the chronic hemodialysis patient? Sodium. Semin Dial 2008;21:226-229.

-21 Lomonte C, Basile C: Do not forget to individualize dialysate sodium prescription. Nephrol Dial Transplant 2011;26:1126-1128.

22 Peixoto AJ, Gowda N, Parikh CR, Santos SF: Long-term stability of serum sodium in hemodialysis patients. Blood Purif 2010;29:264-267.

23 Santos SF, Peixoto AJ: Sodium balance in maintenance hemodialysis. Semin Dial 2010;23:549-555.

24 Jin H, Lee SY, Lee SN, Song JH, Kim MJ, Lee SW: Effect of dialysate sodium concentration on sodium gradient and hemodialysis parameters. Electrolyte Blood Press 2014;12:66-73.

-25 Penne EL, Sergeyeva O: Sodium gradient: a tool to individualize dialysate sodium prescription in chronic hemodialysis patients? Blood Purif 2011;31:86-91.

26 Movilli E, Camerini C, Gaggia P, Zubani R, Feller P, Poiatti P, Pola A, Carli O, Valzorio B, Cancarini G: Role of dialysis sodium gradient on intradialytic hypertension: an observational study. Am J Nephrol 2013;38:413419.

27 Davenport A: Negative dialysate to sodium gradient does not lead to intracellular volume expansion post hemodialysis. Int J Artif Organs 2010;33:700-705.

-28 Kumar S, Khosravi M, Massart A, Potluri M, Davenport A: Are serum to dialysate sodium gradient and segmental bioimpedance volumes associated with the fall in blood pressure with hemodialysis? Int J Artif Organs 2014;37:21-28.

29 Munoz Mendoza J, Arramreddy R, Schiller B: Dialysate sodium: choosing the optimal hemodialysis bath. Am J Kidney Dis 2015;66:710-720.

-30 Gul A, Miskulin DC, Paine SS, Narsipur SS, Arbeit LA, Harford AM, Weiner DE, Schrader R, Horowitz BL, Zager PG: Comparison of prescribed and measured dialysate sodium: a quality improvement project. Am J Kidney Dis 2016;67:439-445.

-31 Agarwal R, Andersen MJ, Bishu K, Saha C: Home blood pressure monitoring improves the diagnosis of hypertension in hemodialysis patients. Kidney Int 2006;69:900-906.

-32 Alborzi P, Patel N, Agarwal R: Home blood pressures are of greater prognostic value than hemodialysis unit recordings. Clin J Am Soc Nephrol 2007;2:1228-1234. 